\title{
Influence of the mineral food nanoadditive "Magnetofood" on the quality indicators of whipped confectionery products
}

\author{
Iryna Tsykhanovska ${ }^{1 *}$, Viktoria Yevlash $^{1}$, Alexandr Alexandrov ${ }^{1}$, and Ravshanbek Alibekov ${ }^{2}$ \\ ${ }^{1}$ Department of Chemistry, Microbiology and Food Hygiene, Kharkiv State University of Nutrition and Trade, Kharkiv, Ukraine \\ ${ }^{2}$ Department of Food Engineering, M. Auezov South Kazakhstan State University, Shymkent, Kazakhstan
}

\begin{abstract}
Investigation of the influence of the mineral food nanoadditive "Magnetofood" on the quality indicators of whipped confectionery products in the technologies of curd dessert and white-pink marshmallow. It was found that the introduction of the additive "Magnetofood" into the prototypes of cottage cheese desserts and white-pink marshmallows in an amount from $0,1 \%$ to $0,2 \%$ by weight of the recipe mixture in comparison with the control improves the structure, texture and appearance of the whipped product; a narrow and symmetric distribution function of air bubbles by diameter $(\mathrm{d}=0,045 \ldots 0,050 \mathrm{M})$ indicates the stabilizing effect of "Magnetofood" nanoparticles. The rational content of the nanoadditive "Magnetofood" has been determined $-0,15 \%$ to the mass of the prescription mixture. The prospects of using "Magnetofood" as an improver and stabilizer of polyphase foam-like structures have been determined.
\end{abstract}

\section{Introduction}

To ensure high consumer properties and competitiveness of whipped confectionery products, it is necessary to solve a number of issues related to stabilizing the polyphase structure and maintaining product quality during transportation and storage [1-7] The use of food nano-additives in whipped confectionery technology is a new and promising direction of research [8-10].

This study solves the problem of stabilization of the polyphase structure of whipped confectionery and the formation of their quality by using the mineral nanoadditive "Magnetofood" (based on oxides of ferrous and ferric iron: $\mathrm{FeO} \cdot \mathrm{Fe}_{2} \mathrm{O}_{3}$ ). "Magnetofood" is an ultrafine powder of dark brown or black color with a particle size of $(70-80) \mathrm{nm}$, with a large specific surface; antioxidant, bacteriostatic, sorption, complexing, stabilizing, emulsifying, water-retaining and fat-retaining properties [8-10].

The purpose of the work is the formation of quality indicators of whipped confectionery products (cottage cheese dessert and white-pink marshmallow) when the mineral food nanoadditive "Magnetofood" is added to the recipe.

To achieve the goal, the following tasks were solved: study the effect of the nano-additives "Magnetofood" on organoleptic characteristics, microstructure, physicochemical and structural-mechanical characteristics of prototypes of whipped curd and marshmallow masses.

\section{Experimental}

*Corresponding author: cikhanovskaja@gmail.com
Object of research: production technology of cottage cheese desserts and white-pink marshmallows (on agar and pectin).

The subject of research is model curd and marshmallow masses with a mass fraction of the food nanoadditive "Magnetofood" $0,10 \% ; 0,15 \% ; 0,20 \%$ to the mass of the recipe mixture. The food nanoadditive "Magnetofood" was introduced in the form of: 1) fat suspension (in curd desserts) with stirring of curd in an amount of $0,2 \mathrm{~g} ; 0,3 \mathrm{~g} ; 0,4 \mathrm{~g}$ per $100,0 \mathrm{~g}$ of the prescription mixture, which is $0 \%$ (control - sample 1); $0,10 \%$ (sample 2); $0,15 \%$ (sample 3); $0,20 \%$ (sample 4 ) food nanoadditive "Magnetofood"; 2) an aqueous suspension based on a 5\% aqueous solution of a gelling agent - agar or pectin (into marshmallows) at the stage of swelling-dissolution of the gelling agent in an amount of $0 \mathrm{~g}$ and $30,0 \mathrm{~g}$ per $1000,0 \mathrm{~g}$ of the prescription mixture, which is $0 \%$ (control - sample 1 for agar and control - sample 3 for pectin); $0,15 \%$ (sample 2 for agar and sample 4 for pectin) food nanoadditive "Magnetofood".

To determine organoleptic (on a 5-point scale, taking into account the weight coefficients of each indicator), physicochemical (total acidity, mass fraction of moisture, density), structural and mechanical (effective viscosity using a Reotest-2 rotary viscometer, mechanical strength and ultimate shear stress - on the AP-4/1 penetrometer, the microstructure of the whipped mass using a microscope) indicators were used generally accepted and standard techniques $[9,10]$.

\section{Results and discussion}

The surface activity of nanoparticles of the food additive "Magnetofood" and their ability to form solvate complexes with protein molecules improves the 
consistency of the curd dessert, which is evident from the organoleptic characteristics (Fig. 1).

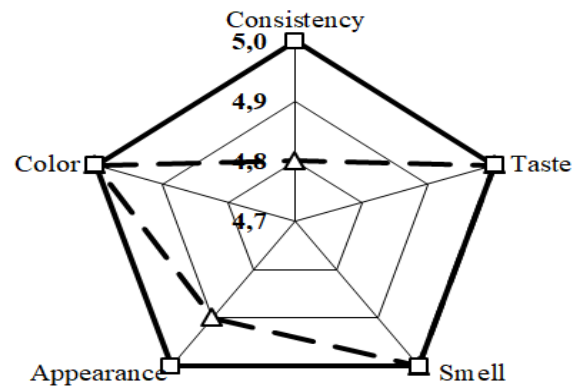

$\longrightarrow$-Sample 1 - Control $\quad \longrightarrow \square-$ Sample 3

Fig. 1. Organoleptic characteristics of prototypes of curd dessert.

The introduction of the food additive "Magnetofood" into the recipe for the curd dessert provides sufficient stability of the product, which can be seen from the narrow distribution curve of the diameters of air bubbles (Fig. 2).

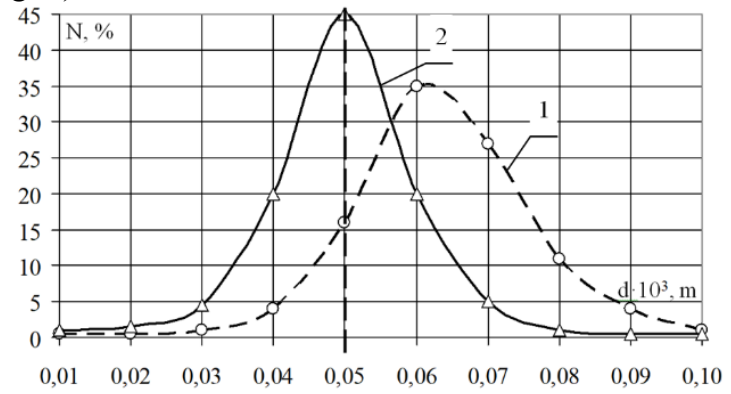

Fig. 2. Distribution of air bubbles by diameter in prototypes of curd dessert: 1 - control, 2 - dessert with $0,15 \%$ "Magnetofood".

The narrow distribution of air bubbles in diameter helps to stabilize the foamy structure of the curd dessert. This is explained by the complementary properties of $\mathrm{Fe}$ atoms of the food additive "Magnetofood" and the formation of coordination and electrostatic bonds of "Magnetofood" nanoparticles with curd proteins, which strengthens the foamy structure of the curd dessert (promoting foaming and fixing air bubbles in the system) [9].

In addition, the introduction of the food additive "Magnetofood" corrects the structural and mechanical characteristics of the curd dessert: with an increase in the mass fraction of the additive "Magnetofood", the following increases: the maximum shear stress is $1,18 \ldots 1,3$ times (which characterizes the strength of bonds in associative complexes of polyphase structures with "Magnetofood" nanoparticles, which have a structureforming ability), the thixotropy coefficient is $1,25 \ldots 1,27$ times compared to the control.

As a result, the stability of the curd product increases and its structure softens somewhat (due to fat binding by "Magnetofood" nanoparticles and the formation of a structured-solvated system) (Fig. 3).

At the same time, the structural and mechanical characteristics of the dessert remain stable during the entire shelf life (24 hours).

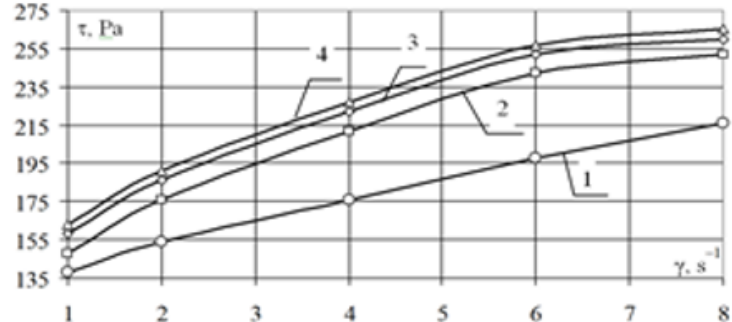

Fig. 3. Shear stress of test samples of curd dessert with different mass fraction of food additive "Magnetofood": 1 control $(0 \%), 2-0,1 \%, 3-0,15 \%, 4-0,2 \%$.

Thus, the introduction of the food additive "Magnetofood" improves the organoleptic characteristics, stabilizes the foamy structure of the curd dessert, including during storage; promotes the formation of stable various forms of the product.

It has been experimentally established that the introduction of the food additive "Magnetofood" in the amount of $0,10 \% ; 0,15 \% ; 0,20 \%$ of the mass of raw materials affects: sedimentation stability, viscosity, thixotropic properties of aqueous suspensions, in particular agar and pectin. A rational amount of the food additive "Magnetofood" has been established $-0,15 \%$ of the mass of raw materials. This served as the basis for the introduction of the food additive "Magnetofood" in gummy-pastilles in the form of suspensions based on a $5 \%$ aqueous solution of a gelling agent (agar, pectin) - in a rational amount of $30,0 \mathrm{~g}$ of an aqueous suspension per $1000,0 \mathrm{~g}$ of a recipe mixture [10].

The results of the organoleptic assessment of the quality of test samples of white-pink marshmallow are shown in Fig. 4.

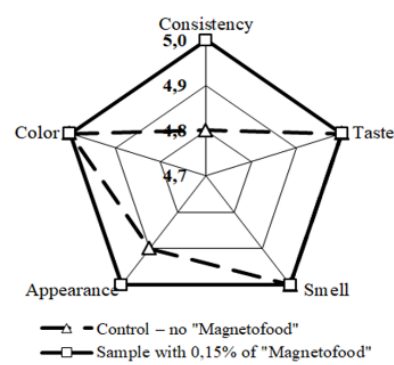

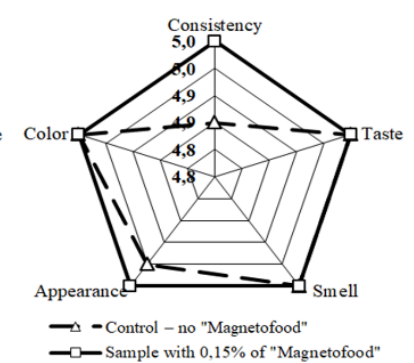

b
Fig. 4. Organoleptic indicators of test samples of white-pink marshmallow with various gelling agents in comparison with control samples: $\mathrm{a}$ - on agar; $\mathrm{b}$ - on pectin.

From the data in Fig. 4 it can be seen that the introduction of $0,15 \%$ food additive "Magnetofood" improves the organoleptic characteristics of the product in comparison with the control: marshmallow is uniform, uniformly white with a cream shade and light pink color; has a soft, uniform consistency and fine-mesh structure; rounded, without deformation, with a clear outline; smooth surface without damage and hardening on the edges; pleasant pronounced taste and smell characteristic of marshmallows.

According to the organoleptic analysis data, the rational content of the food additive "Magnetofood" is $0.15 \%$ of the mass of the recipe mixture, which is 
confirmed by studies of the foaming ability and foam stability of egg white on model systems with different gelling agents and with different amounts of the food additive "Magnetofood" using mathematical modeling [10].

Table 1 shows the main physical, chemical and technological parameters of prototypes of white-pink marshmallow with various gelling agents.

Table 1. Physicochemical and technological indicators of prototypes of white-pink marshmallow.

\begin{tabular}{|c|c|c|c|c|}
\hline \multirow{2}{*}{} & \multicolumn{3}{|c|}{ Prototypes of white-pink marshmallow } \\
\cline { 2 - 5 } & \multicolumn{2}{|c|}{ on agar } & \multicolumn{2}{c|}{ on pectin } \\
\cline { 2 - 5 } Indicator & $\begin{array}{c}\text { Sample 1 } \\
\text { - control }\end{array}$ & $\begin{array}{c}\text { Sample 2 } \\
\text { with } \\
0,15 \% \\
\text { "Magnetof } \\
\text { ood" }\end{array}$ & $\begin{array}{c}\text { Sample 3 } \\
\text { - control }\end{array}$ & $\begin{array}{c}\text { Sample 4- } \\
\text { with 0,15\% } \\
\text { "Magnetofoo } \\
\text { d" }\end{array}$ \\
\hline $\begin{array}{c}\text { Moisture } \\
\text { content, \% }\end{array}$ & $17,0 \pm 0,8$ & $17,4 \pm 0,8$ & $17,0 \pm 0,8$ & $17,5 \pm 0,8$ \\
\hline $\begin{array}{c}\text { Total } \\
\text { acidity, } \\
\text { deg. }\end{array}$ & $0,7 \pm 0,03$ & $0,6 \pm 0,02$ & $5,90 \pm 0,3$ & $5,30 \pm 0,2$ \\
\hline $\begin{array}{c}\text { Density, } \\
\text { kg/m }\end{array}$ \\
$\begin{array}{c}\text { (smallest } \\
\text { value) }\end{array}$ & $545 \pm 12$ & $485 \pm 8$ & $550 \pm 12$ & $480 \pm 8$ \\
\hline $\begin{array}{c}\text { Whipping } \\
\text { duration, } \\
\text { x60s }\end{array}$ & 16,0 & 14,0 & 10,0 & 8,0 \\
\hline $\begin{array}{c}\text { Strength, } \\
\text { kPa }\end{array}$ & $9,0 \pm 0,5$ & $10,8 \pm 0,6$ & $6,5 \pm 0,3$ & $7,4 \pm 0,4$ \\
\hline $\begin{array}{c}\text { Moisture } \\
\text { content, \% }\end{array}$ & $17,0 \pm 0,8$ & $17,4 \pm 0,8$ & $17,0 \pm 0,8$ & $17,5 \pm 0,8$ \\
\hline
\end{tabular}

Whence it can be seen that when the food additive "Magnetofood" is introduced, the density decreases by $(1,12 \ldots 1,15)$ times and the duration of whipping by $(1,5 \ldots 2,5) \times 60 \mathrm{~s}$ due to the interaction of the nanoparticles "Magnetofood" with molecules of egg white, which promotes the branching of the main chains of its macromolecules and slows down the process of liquid draining and thinning of the walls of air bubbles. The use of the food nanoadditive "Magnetofood" increases the strength of the foam by $(1,1 \ldots 1,2)$ times due to the "cluster-philicity" of the nanoparticles of the food additive "Magnetofood", which increases the viscosity of the gelling agent in the Gibbs-Plateau channels, which slows down the syneresis process and stabilizes the gel frame foam-like structure.

Table 2 the results of change of the volume of experimental samples of marshmallow masses during storage for a regulated period of 60 days.

As can be seen from the data of the Table 2 the introduction of the food nanoadditive "Magnetofood" stabilizes the structure of prototypes of marshmallow masses by improving the foaming and fixation of air bubbles in the system under the action of "Magnetofood" nanoparticles. The functionality of the food additive "Magnetofood" is manifested primarily in the reduction of surface tension. The destruction of the foam is caused by the processes of diffusion of air, the outflow of liquid from the walls of the bubbles (viscosity of the liquid) and the enlargement of bubbles due to fusion.

Table 2. Physicochemical and technological indicators of prototypes of white-pink marshmallow.

\begin{tabular}{|c|c|c|c|c|}
\hline \multirow{3}{*}{$\begin{array}{l}\text { Shelf } \\
\text { life, } \\
\text { days }\end{array}$} & \multicolumn{4}{|c|}{$\begin{array}{l}\text { The volume of prototypes of marshmallow masses, } \\
\qquad \mathrm{cm}^{3}\end{array}$} \\
\hline & \multicolumn{2}{|r|}{ on agar } & \multicolumn{2}{|c|}{ on pectin } \\
\hline & $\begin{array}{l}\text { Sample } 1 \\
\text { - control }\end{array}$ & $\begin{array}{c}\text { Sample } 2- \\
\text { with } 0,15 \% \\
\text { "Magnetofood" }\end{array}$ & $\begin{array}{l}\text { Sample } 3 \\
\text { - control }\end{array}$ & $\begin{array}{c}\text { Sample } 4- \\
\text { with } 0,15 \% \\
\text { "Magnetofood" }\end{array}$ \\
\hline 0 & $100 \pm 5$ & $100 \pm 5$ & $100 \pm 5$ & $100 \pm 5$ \\
\hline 20 & $81,7 \pm 4$ & $98,2 \pm 5$ & $80,4 \pm 4$ & $97,2 \pm 5$ \\
\hline 40 & $76,4 \pm 3$ & $93,6 \pm 5$ & $75,2 \pm 3$ & $92,8 \pm 5$ \\
\hline 60 & $68,2 \pm 2$ & $86,8 \pm 4$ & $67,0 \pm 3$ & $85,6 \pm 5$ \\
\hline
\end{tabular}

In addition, a rather narrow peak, both for control and for prototypes $(2,4)$ with $0.15 \%$ food nanoadditive "Magnetofood" stabilizes, indicates a uniform overrun of marshmallows. Moreover, due to the higher viscosity and lower surface tension, the stability of the foam in the prototypes with the food nanoadditive "Magnetofood" is higher. That is, the food nanoadditive "Magnetofood" stabilizes the foamy structure of marshmallows, including during the storage period established by the regulations.

The viscosity and mechanical strength of experimental samples of marshmallow were studied. After the formation of the whipped mass, the frame is gradually fixed, since the liquid films separating the air bubbles contain a gelling agent, which ensures the transition of the mass into a gel-like state. Fig. 5. shows the strength ( $\tau$, $\mathrm{kPa}$ ) of prototypes of marshmallow masses in the process of aging $(\tau \times 60 \mathrm{~s})$.

From Fig. 5 it can be seen that the introduction of the food additive "Magnetofood" accelerates the gelation process by $(2,0 \ldots 2,5) \times 60 \mathrm{~s}$ on agar and by $(2.0 \ldots 2,2) \times 60$ $\mathrm{S}$ on pectin; increases the maximum shear stress by $(11,9 \ldots 12,6) \%$ - on agar and $(8,2 \ldots 9,1) \%$ - on pectin, which is associated with the formation of supramolecular associates with "Magnetofood" nanoparticles. As a result, the gelation process is accelerated and the strength of the whipped mass increases. In addition, the introduction of the food additive "Magnetofood" increases the effective viscosity of marshmallow masses by $(1,35 \ldots 1,55)$ times compared to the control, which is associated with the structure-forming effect of nanoparticles "Magnetofood", leading to the aggregation of polysaccharides and an increase in roughness of their channels. As a result, the stability of foam films increases, and an increase in the gel-forming ability of pectin and agar allows increasing the viscosity in the Gibbs-Plateau channels, stabilizes the gel frame of the foam structure and slows down the syneresis process [6].

On the basis of the research carried out, formulations were compiled and technological schemes for the production of white-pink marshmallows (on agar and pectin) using the food nanoadditive "Magnetofood" were developed. 

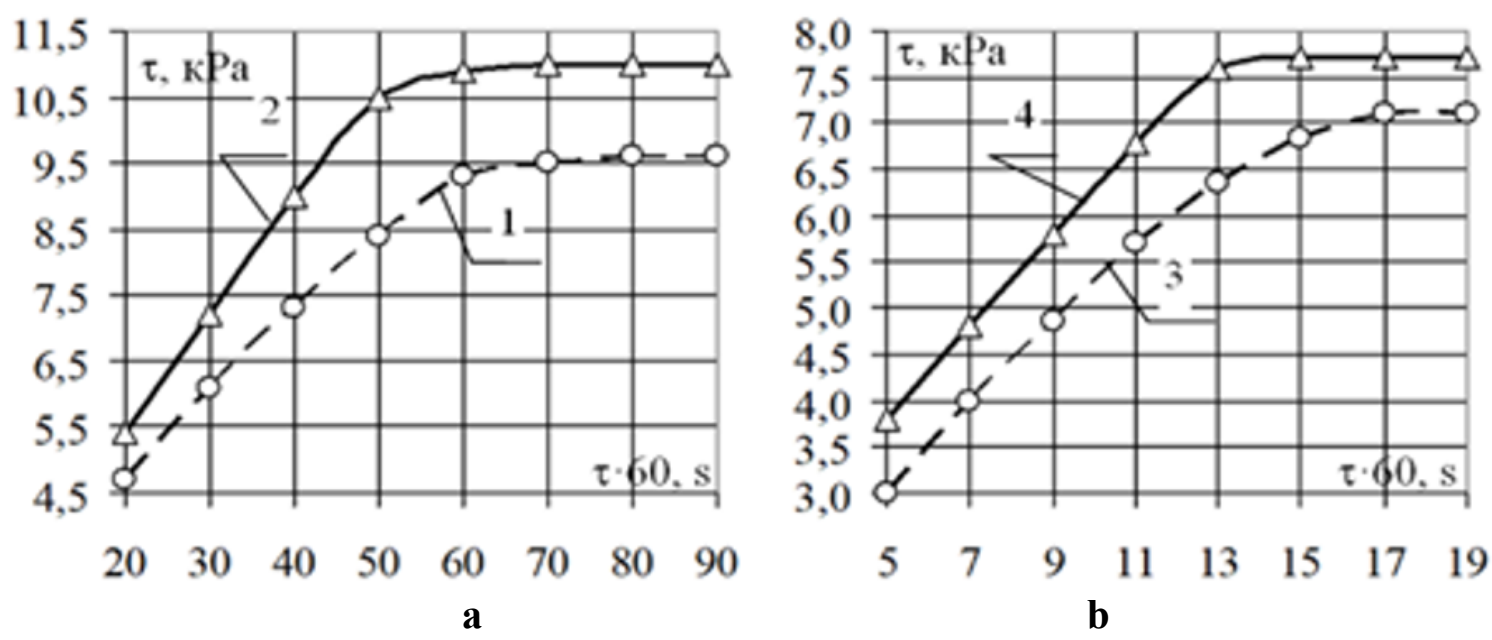

Fig. 5. Dependence of strength on the aging duration of prototypes of whipped masses: a - on agar (1 - sample 1control, 2 - sample 2 with 0,15\% "Magnetofood"); b - on pectin (3 - sample 3 -control, 4 - sample 4 with $0,15 \%$ "Magnetofood".

\section{Conclusion}

The functionality of the mineral food nanoadditive "Magnetofood" has been proven in technologies: curd dessert and white-pink marshmallow. Organoleptic indicators of finished products and dispersed characteristics of foam structures in curd dessert and in marshmallows were determined with the introduction of the food additive "Magnetofood": the distribution function of air bubbles in diameter is narrow and symmetrical, diameter $\mathrm{d}=(45 \ldots 50) \times 10^{-3} \mathrm{~m}$ is a fundamental factor indicating the stabilizing effect of "Magnetofood" nanoparticles. A rational amount of the food additive "Magnetofood" in the formulations of whipped confectionery products $(0,15 \%)$ has been established.

It has been established that the food nanoadditive "Magnetofood" affects the structural and mechanical properties of whipped confectionery: in curd desserts, with an increase in the mass fraction of the food additive "Magnetofood", the maximum shear stress is increased by $(1,18 \ldots 1,3)$ times and the thixotropy coefficient is $1,25 \ldots 1,27$ times compared to the control; in white-pink marshmallows, they increase - the strength of the foam structure is $(1,1 \ldots 1,2)$ times and the effective viscosity of marshmallows is $(1,35 \ldots 1,55)$ times compared with the control. This has a positive effect on the texture of the product and extends the shelf life of its freshness.

It has been determined that with the introduction of the food nanoadditive "Magnetofood" in the marshmallow masses, the following decrease: the density is $(1,12 \ldots 1,15)$ times and the duration of whipping by $(1,5 \ldots 2,5) \times 60 \mathrm{~s}$ by compared with control.

\section{References}

1. Yu. Hachak, Ya. Vavrychevych, N. Prokopiuk, Sci. Messenger LNUVMBS, 18, 53-59 (2016)

2. M. Soloveva, Dairy Ind., 5, 23-26 (2013)

3. K. Ramachandraiah, M.-J. Choi, G.-P. Hong, Trends Food Sci. Technol., 71, 25-35 (2018)

4. L. R. Ramos, J. S. Santos, H. Daguer, A.C.Valese, D. Granato, Food Chem., 221, 950-958 (2017)

5. H. Park, M. Lee, K. T. Kim, E. Park, H. D. Paik, JDS, 101, 8702-8710 (2018)

6. S-M.T. Gharibzahedi, M. Koubaa, F. J. Barba, R. Greiner, S. Roohinejad, Int. J. Biol. Macromol., 107(B), 2364-2374 (2018)

7. D. Granato, J. S. Santos, R. Ds. Salem, A. M. Mortazavian, A. G. Cruz, Curr. Opin. Food Sci., 19, 1-7 (2018)

8. N. Ilyukha, I. Tsykhanovska, Z. Barsova, V. Kovalenko, EastEuropean J. Adv. Techol., 48, 32-35 (2010)

9. O. Aleksandrov, I. Tsykhanovska, N. Kaida, V. Yevlash, Sci. works Univ. Food Technol., 25, 169-179, (NUKhT, Kyiv, 2019)

10. I. Tsykhanovska, V. Yevlash, O. Aleksandrov, N. Kaida, Z. Kovalenko, Sci. works Univ. Food Technol., 25, 186-203, (NUKhT, Kyiv, 2019) 